\title{
Macroinvertebrate Richness Importance in Coastal Tropical Streams of Esmeraldas (Ecuador) and Its Use and Implications in Environmental Management Procedures
}

\author{
Carlos Martínez-Sanz, ${ }^{1}$ Sara María Puente-García, ${ }^{2}$ \\ Eduardo Rodolfo Rebolledo, ${ }^{1}$ and Pedro Jiménez-Prado ${ }^{1}$ \\ ${ }^{1}$ Faculty of Environmental Science, Pontifical University Catholic of Ecuador in Esmeraldas (PUCESE), \\ C/ Espejo y Santa Cruz S/N, 080150 Esmeraldas, Ecuador \\ ${ }^{2}$ Area of Ecology, Faculty of Biology and Environmental Science, University of León, Campus de Vegazana, S/N, 24071 León, Spain \\ Correspondence should be addressed to Carlos Martínez-Sanz; cmars@unileon.es
}

Received 18 July 2013; Revised 5 December 2013; Accepted 8 December 2013; Published 8 January 2014

Academic Editor: Ram C. Sihag

Copyright @ 2014 Carlos Martínez-Sanz et al. This is an open access article distributed under the Creative Commons Attribution License, which permits unrestricted use, distribution, and reproduction in any medium, provided the original work is properly cited.

\begin{abstract}
This study was aimed at determining the performance of some indices and community attributes frequently used to assess river quality and test the role of macroinvertebrate taxa richness as element of bioindication in several coastal tropical streams of western Esmeraldas (Ecuador). In addition, a macroinvertebrate taxon list of this region was provided for the first time. Thirteen sampled points distributed across nine streams were selected for this study and nineteen parameters and attributes of bioindication were tested. The differences between nonimpact and impact places were evaluated mainly using one-way analysis of variance. Jackknife 2 and Clench were used to estimate the regional richness and the quality of the inventory, respectively. Seventy taxa (principally genus and family) of the main groups of macroinvertebrates were collected. Measured richness and family richness were the best metric followed by Biological Monitoring Working Party/Colombia (BMWP/Col), Odonata richness, Shannon-Weiner, and EPT richness (Ephemeroptera + Plecoptera + Trichoptera) indices. Only a slight right trend (Ephemeroptera, Trichoptera, and Chironomidae attributes) or incorrect performances (Average Score Per Taxon (ASPT) and \% EPT) were showed by frequently used metrics. Finally, several recommendations were made about taxonomic level used, the ranks of quality of taxa richness, and the effort-results relationship in the field of bioindication.
\end{abstract}

\section{Introduction}

Global change, population growth, and industrial development are currently exerting great impacts on natural ecosystems, especially on aquatic systems [1]. Agricultural practices, livestock and domestic discharges, the felling of trees, exotic species introductions, and direct erosion have caused increase in the organic matter and suspended solids in water, resulting in strong alterations in the ecological functioning of aquatic systems [2]. Coastal river basins are among the most dynamic aquatic ecosystems on earth, with enormous spatial and temporal complexity, but they are often influenced by continental run-off waters which are rich in nutrients derived from urban, agricultural, and industrial activity [3]. The causes and effects of pollution in tropical rivers have been studied by several researchers, mainly with respect to particulate and suspended matter, the chemical dynamics in waters connected with organic matter content, nutrient loading, and $\mathrm{pH}$ [4]. In Latin America, such rivers pass through a strong water quality degradation gradient due to increasing exploitation of the resources and the excessive water pollution [5], especially in Ecuador where only 5\% of the wastewater in the region is subjected to some type of treatment. This is surprising since the water law establishes the prohibition of sewage discharges in rivers and lakes (in Title II of the Conservation and Water Pollution Chapter II Article 22). The province of Esmeraldas (Ecuador) is not exempted from these impacts. In recent decades, its rivers 
have been severely altered by numerous human activities, such as oil and fuel spills, sewage and industrial waste disposals, introduction of alien species, and illegal extractive activities [6]. In addition, there is no consistent wastewater treatment system in the region.

It is, therefore, necessary to use tools that can reveal the overall effect of human impact on the aquatic ecosystem [7]. Benthic macroinvertebrates have been considered as excellent indicators of water quality. Their study is a key to the work of bioindication and evaluation of the aquatic ecosystem [8] and they constitute the most suitable group of organisms for evaluating river water quality for organic contamination [9]. There are several studies that have used macroinvertebrate communities to assess the effect of organic waste on the coastal streams of South American countries. Most of them have been carried out in Colombia [10], Chile [9], Argentina [11], Uruguay [12], Peru [13], Brazil [14], and Bolivia [15] but still few in Ecuador $[5,16]$ and none on its tropical coastal streams. There are two large groups of techniques used to assess the biological quality using macroinvertebrates: community attributes and biological indices [17]. The use of simple metrics based on several community attributes, such as taxa richness or number of taxa of some selected groups of organisms, is a widely adopted technique in South America (e.g., $[13,18])$, but its performance must still be tested in these regions due to the latitudinal and longitudinal patterns of taxa [19] and their wide distribution range [20]. On the other hand, among all the biological indices developed to measure the river quality, the most commonly used are those based on the Biological Monitoring Working Party (BMWP) [21]. The BMWP has been adopted in many countries such as Spain (IBMWP [22]) or Australia (SIGNAL [23]). In South America also, there are several examples of its application in biomonitoring [24], for example, in Patagonian Andes region (IAP and BMPS [25]), Argentina [26], Colombia (BMWP/Col [10]), Brazil [27], and Andean region of Peru, and Ecuador [16]. However, in Ecuador for its coastal tropical rivers, neither these indices have been adopted nor any study has been made on its performance. Despite this, these are widely used by environmental technician and auditors in several studies, even though these versions were developed for Europe [28].

The aim of this study was to test the performance of some of the most commonly used macroinvertebrate indices and community attributes to assess the water quality of coastal tropical streams of western Ecuador. In addition, for the first time, a macroinvertebrate taxon list of these systems will be provided for the above-mentioned fluvial systems and region. The main purpose of this paper is to establish more adequate techniques and recommendations using macroinvertebrate to devise a suitable management strategy for the aquatic resources (when the Ecuadorian legislation is applied). At the same time, there is also an interest in directly verifying the role of biodiversity as an environmental assessment measure. The majority of these evaluation techniques are based on the sensitivity and tolerance of macroinvertebrates to pollution. But we think and predict that in Ecuador, one of the areas with the greatest biodiversity in the world, other attributes

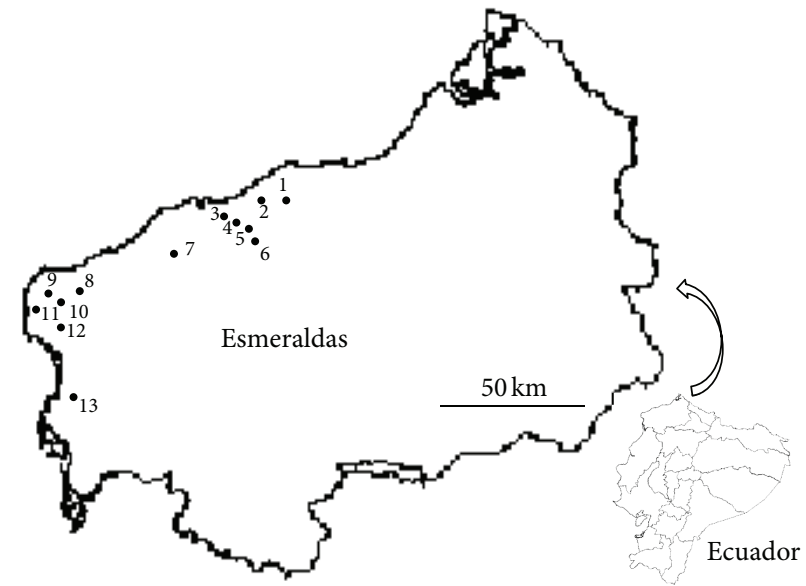

Figure 1: Area of study and sample points. 1: Río Verde (RV), 2: Estero Camarones (Ca), 3: Estero Tachina I (T-I), 4: Estero Tachina II (T-II), 5: Estero Tachina III (T-III), 6: Estero Tachina IV (T-IV), 7: Estero Tabiazo (Tbz), 8: Estero Chipa (Ch), 9: Estero Plátano Bajo $(\mathrm{EPb}), 10$ : Estero Plátano Alto (EPa), 11: Estero Quinge (Q), 12: San Francisco (SF), and 13: Estero Mompiche (M).

relating to the community structure, such as taxa richness, should also have good performance.

\section{Materials and Methods}

2.1. Study Area. Thirteen sampling points distributed across nine streams were selected for this study (Figure 1). All of them are located in the province of Esmeraldas, Ecuador (South America). The area is located in the dry tropical forest life zone [29] on the west pacific coast, where shallow and short streams with variable seasonal flow are predominant [30]. Table 1 shows some characteristics of these streams and the presence or absence of human impact.

2.2. Macroinvertebrate Sampling. Sampling at all the points was done once in October 2012 to coincide it with the dry season, the recommended period to carry out bioindication studies in this region [31]. Benthic macroinvertebrate samples were collected with a pond net (FBA standard, mesh size $500 \mu \mathrm{m}$ ) following a multihabitat time-limited sampling [32]. Each point, proportionally distributed among the main habitats in the river, was sampled during three minutes' time [33], although in all cases the predominant substrate was of gravel, stones, and rock (hard substrate). Macroinvertebrates were separated and counted under a binocular microscope (10x) and identified to genus (60\%) and family (40\%) levels. The principal guides and books used were by Fernández and Domínguez [34] and Holzenthal et al. [35].

2.3. Metric Selection. We compared the performance of 19 parameters frequently used to assess river quality (Table 2). We calculated the total abundance and richness of the macroinvertebrate community as well as the percentage of abundance and richness of the most relevant taxa used for bioindication [17]. Diversity 
TABLE 1: Some characteristics of the streams included in the study.

\begin{tabular}{|c|c|c|c|c|c|c|c|c|}
\hline Study area* & $\mathrm{UTM}^{* *}$ & Altitude (m) & $\begin{array}{l}\text { Temp. } \\
\left({ }^{\circ} \mathrm{C}\right)\end{array}$ & $\mathrm{pH}$ & Depth $(\mathrm{cm})$ & Width (m) & Substrate type & $\begin{array}{l}\text { Human } \\
\text { impact }^{* * *}\end{array}$ \\
\hline $\mathrm{RV}$ & $674195 / 103203$ & 25 & 25 & 7.3 & 90 & 6 & Stony and sandy & IMP \\
\hline $\mathrm{Ca}$ & $659722 / 107374$ & 80 & 25.3 & 7 & 40 & 5 & Stony & IMP \\
\hline T-I & $657039 / 103944$ & 75 & 27 & 6.8 & 32 & 6.5 & Stony & IMP \\
\hline T-II & $657299 / 103546$ & 81 & 26.5 & 7 & 30 & 6 & Stony & IMP \\
\hline T-III & $659162 / 099949$ & 164 & 28 & 6.9 & 31 & 5 & Stony & Non-IMP \\
\hline T-IV & $659730 / 099523$ & 195 & 28.2 & 7.2 & 30 & 4 & Stony & Non-IMP \\
\hline $\mathrm{Tbz}$ & $644956 / 087091$ & 40 & 27 & 7.1 & 90 & 9 & Stony & Non-IMP \\
\hline $\mathrm{Ch}$ & $605058 / 082185$ & 90 & 26 & 7 & 32 & 4.3 & Stony & Non-IMP \\
\hline $\mathrm{EPb}$ & $601471 / 083773$ & 30 & 26 & 7.3 & 27 & 5.2 & Stony & IMP \\
\hline $\mathrm{EPa}$ & $602116 / 082477$ & 49 & 25 & 7.2 & 31 & 4.1 & Stony & Non-IMP \\
\hline Q & $602108 / 079216$ & 28 & 25 & 6.7 & 40 & 3.7 & Stony and sandy & Non-IMP \\
\hline SF & $609060 / 077145$ & 45 & 25.8 & 7 & 42 & 7.9 & Stony & Non-IMP \\
\hline M & $609754 / 055039$ & 25 & 24.7 & 6.8 & 28 & 4.4 & Stony & IMP \\
\hline
\end{tabular}

* Río Verde (RV), Estero Camarones (Ca), Estero Tachina I (T-I), Estero Tachina II (T-II), Estero Tachina III (T-III), Estero Tachina IV (T-IV), Estero Tabiazo (Tbz), Estero Chipa (Ch), Estero Plátano Bajo (EPb), Estero Plátano Alto (EPa), Estero Quinge (Q), San Francisco (SF), and Estero Mompiche (M). ${ }^{* *}$ Universal Transverse Mercator Geographic Coordinate System. ${ }^{* * *}$ IMP: human impact present; Non-IMP: human impact not present.

TABLE 2: Values of the metrics measured in each stream.

\begin{tabular}{|c|c|c|c|c|c|c|c|c|c|c|c|c|c|}
\hline Attribute & $(\mathrm{RV})$ & $(\mathrm{Ca})$ & $(\mathrm{T}-\mathrm{I})$ & $(\mathrm{T}-\mathrm{II})$ & (T-III) & $(\mathrm{T}-\mathrm{IV})$ & $(\mathrm{Tbz})$ & $(\mathrm{Ch})$ & $(\mathrm{EPb})$ & $(\mathrm{EPa})$ & $(\mathrm{Q})$ & $(\mathrm{SF})$ & $(\mathrm{M})$ \\
\hline Measured richness & 19 & 14 & 20 & 16 & 28 & 32 & 30 & 25 & 17 & 32 & 28 & 32 & 23 \\
\hline Family richness & 15 & 13 & 16 & 13 & 22 & 24 & 22 & 19 & 15 & 26 & 21 & 22 & 20 \\
\hline Total abundance & 156 & 196 & 640 & 156 & 263 & 385 & 445 & 142 & 108 & 597 & 220 & 791 & 269 \\
\hline Shannon-Wiener & 4 & 2 & 3 & 3 & 4 & 4 & 4 & 4 & 3 & 4 & 4 & 3 & 4 \\
\hline BMWP/Col & 104 & 84 & 115 & 78 & 159 & 179 & 153 & 134 & 91 & 183 & 130 & 145 & 141 \\
\hline ASPT & 5 & 6 & 6 & 5 & 6 & 6 & 5 & 5 & 5 & 6 & 5 & 5 & 6 \\
\hline EPT richness & 13 & 8 & 9 & 11 & 9 & 11 & 10 & 7 & 10 & 9 & 4 & 5 & 10 \\
\hline EPT (\%) & 7 & 4 & 9 & 8 & 9 & 11 & 13 & 11 & 5 & 10 & 9 & 10 & 10 \\
\hline Richness of Ephemeroptera & 6 & 3 & 6 & 7 & 6 & 5 & 9 & 6 & 3 & 5 & 8 & 8 & 6 \\
\hline Richness of Trichoptera & 1 & 1 & 3 & 1 & 2 & 5 & 4 & 4 & 2 & 5 & 1 & 2 & 4 \\
\hline Richness of Plecoptera & 0 & 0 & 0 & 0 & 1 & 1 & 0 & 1 & 0 & 0 & 0 & 0 & 0 \\
\hline Richness of Odonata & 2 & 3 & 1 & 1 & 2 & 4 & 3 & 3 & 3 & 4 & 4 & 3 & 2 \\
\hline Richness of Coleoptera & 1 & 1 & 3 & 1 & 4 & 4 & 1 & 3 & 1 & 3 & 2 & 2 & 2 \\
\hline Percentage of Ephemeroptera & 25 & 4 & 68 & 51 & 29 & 25 & 34 & 32 & 9 & 14 & 60 & 60 & 53 \\
\hline Percentage of Trichoptera & 4 & 1 & 10 & 1 & 2 & 8 & 7 & 18 & 5 & 14 & 1 & 7 & 11 \\
\hline Percentage of Chironomidae & 20 & 1 & 13 & 4 & 34 & 25 & 36 & 15 & 11 & 12 & 5 & 4 & 5 \\
\hline Percentage of Odonata & 2 & 3 & 1 & 2 & 2 & 8 & 2 & 13 & 5 & 5 & 4 & 1 & 9 \\
\hline Percentage of Coleoptera & 6 & 26 & 2 & 9 & 15 & 19 & 6 & 14 & 44 & 9 & 5 & 6 & 10 \\
\hline Percentage of Plecoptera & 0 & 0 & 0 & 0 & 0 & 1 & 0 & 2 & 0 & 0 & 0 & 0 & 0 \\
\hline$\% R$-Jack $2^{*}$ & 20 & 15 & 22 & 17 & 30 & 34 & 32 & 27 & 18 & 34 & 30 & 34 & 25 \\
\hline
\end{tabular}

* $\% R$-Jack 2 is the percentage of richness measured in relation to the regional richness estimation (Jack $2=93$ taxa). Abbreviations for study areas are as in Table 1.

was estimated using the Shannon-Wiener index. In addition, we calculated BMWP/Col [10], Average Score Per Taxon (ASPT) [22], and EPT (richness and percentage of Ephemeroptera + Plecoptera + Trichoptera) indices, also widely used in South America to assess the rivers quality. On the other hand, a cornerstone was to assign the locations with and without impacts, the types of impact, and their degree. We chose river points distant from large populations and the effect of industrial activity, considering only the impact of little urban-domestic activities and livestock-agricultural at small scale, all of them without wastewater treatment system [6]. Assigning a level of impact in these rivers basin is almost impossible; therefore, we established two realistic and more practical situations: 
TABLE 3: Macroinvertebrate taxa and total number of individuals collected in the study area.

\begin{tabular}{|c|c|c|c|}
\hline Class/order & Family & Genus & Number \\
\hline \multirow[t]{4}{*}{ Cl. Gastropoda } & F. Thiaridae & & 420 \\
\hline & F. Hydrobiidae & & 29 \\
\hline & F. Neritidae & & 53 \\
\hline & F. Planorbidae & & 4 \\
\hline \multirow[t]{2}{*}{ Cl. Bivalvia } & F. Sphaeriidae & & 5 \\
\hline & F. Corbiculidae & & 19 \\
\hline \multirow[t]{2}{*}{ O. Decapoda } & F. Palaemonidae & Macrobrachium & 85 \\
\hline & F. Atyidae & Caridina & 2 \\
\hline \multirow{14}{*}{ O. Ephemeroptera } & F. Leptophlebiidae & Farrodes & 630 \\
\hline & & Hagenulopsis & 80 \\
\hline & & Traverella & 2 \\
\hline & & Thraulodes & 11 \\
\hline & & Atopophlebia & 5 \\
\hline & F. Leptohyphidae & Leptohyphes & 101 \\
\hline & & Tricorythodes & 608 \\
\hline & & Traverhyphes & 141 \\
\hline & F. Caenidae & Caenis & 6 \\
\hline & F. Baetidae & Callibaetis & 4 \\
\hline & & Guajirolus & 34 \\
\hline & & Camalobaetidus & 10 \\
\hline & & Harpagobaetis & 62 \\
\hline & & Fallceon & 86 \\
\hline O. Plecoptera & F. Perlidae & Anacroneuria & 8 \\
\hline \multirow[t]{9}{*}{ O. Odonata } & F. Protoneuridae & & 3 \\
\hline & F. Platystictidae & Palaemnema & 12 \\
\hline & F. Megapodagrionidae & & 1 \\
\hline & F. Calopterygidae & & 3 \\
\hline & F. Coenagrionidae & Argia & 73 \\
\hline & F. Gomphidae & Epigomphus & 4 \\
\hline & F. Libellulidae & Perithemis & 41 \\
\hline & & Brachymesia & 1 \\
\hline & & Otros n.i. & 16 \\
\hline \multirow[t]{9}{*}{ O. Heteroptera } & F. Naucoridae & & 45 \\
\hline & F. Corixidae & & 9 \\
\hline & F. Gerridae & Trepobates & 71 \\
\hline & & Brachymetra & 7 \\
\hline & & Gerris & 3 \\
\hline & F. Veliidae & Velia & 77 \\
\hline & & Microvelia & 5 \\
\hline & & Rhagovelia & 34 \\
\hline & F. Hebridae & & 6 \\
\hline O. Megaloptera & F. Corydalidae & & 2 \\
\hline O. Lepidoptera & F. Pyralidae & & 15 \\
\hline \multirow[t]{5}{*}{ O. Coleoptera } & F. Psephenidae & & 53 \\
\hline & F. Elmidae & & 323 \\
\hline & F. Hydrophilidae & & 8 \\
\hline & F. Ptilodactilidae & & 7 \\
\hline & F. Dryopidae & & 37 \\
\hline
\end{tabular}


TABLe 3: Continued.

\begin{tabular}{|c|c|c|c|}
\hline Class/order & Family & Genus & Number \\
\hline \multirow[t]{9}{*}{ O. Trichoptera } & F. Calamoceratidae & Phylloicus & 5 \\
\hline & F. Philopotamidae & Chimarra & 13 \\
\hline & F. Hydropsichidae & Smicridea & 188 \\
\hline & & Leptonema & 7 \\
\hline & F. Polycentropodidae & Polycentropus & 9 \\
\hline & F. Glossosomatidae & Protoptila & 31 \\
\hline & F. Hydroptilidae & Metrichia & 3 \\
\hline & & Hydroptila & 74 \\
\hline & F. Leptoceridae & & 12 \\
\hline \multirow[t]{13}{*}{ O. Diptera } & F. Chironomidae & Tanypodinae & 264 \\
\hline & & Orthocladiinae & 179 \\
\hline & & Chironominae & 194 \\
\hline & F. Ceratopogonidae & & 13 \\
\hline & F. Limoniidae & Hexatomini & 47 \\
\hline & & Eriopterini & 35 \\
\hline & F. Empididae & & 9 \\
\hline & F. Sciomycidae & & 1 \\
\hline & F. Simulidae & & 1 \\
\hline & F. Stratiomyidae & & 12 \\
\hline & F. Psychodidae & & 3 \\
\hline & F. Dixidae & & 3 \\
\hline & F. Culicidae & & 1 \\
\hline
\end{tabular}

without impact (Non-IMP) (without any influence of human impact) and with impact (IMP) (with some degree of very slight human impact, e.g., discharge of isolated farms and presence of sparse cattle or people frequently doing little domestic cleaning in the littoral waters).

2.4. Richness Estimation. In addition to observed richness of macroinvertebrate, measures of estimated richness were calculated using nonparametric methods [36, 37]. In the present study, Jack 2 [38] was used to estimate the regional richness of a number of samples (13 rivers point) to obtain real percentages of the fauna collected in each of the streams (Table 2). It was calculated over 100 randomized iterations of the species accumulation using EstimateS ver. 8 [39]. In addition, we used the asymptotic accumulation function of Clench to obtain information about the quality of our inventory [38].

2.5. Data Analysis. The responses of the several metrics and indices to assess the streams quality were graphically explored by means of box plots, showing mean value, standard error, and standard deviation of the metrics within each river category (IMP and Non-IMP). One-way analysis of variance (ANOVA) was applied to detect significant differences $(P<$ $0.01)$. The assumptions of normality and variance homogeneity were tested using the Kolmogorov-Smirnov and Levene's tests, respectively. The statistical processing was performed with the STATISTICA 6.0 package. In addition, we used significant Pearson and Spearman's correlation $(P=0.05)$ to test the degree of relationship between variables.

\section{Results}

3.1. Macroinvertebrate Community. We collected 70 taxa from the 13 sampled points, finding high total abundance (4365 organisms). Table 3 includes a list of the taxa collected in the study area; it is the first report on the aquatic benthic invertebrates in this region.

3.2. Response of the Metrics. Figure 2 shows the differences in the responses of the studied metrics between impact (IMP) and nonimpact (Non-IMP) river points. Only the taxa and index significantly differing from these two situations are represented. In addition, attributes classically used and relevant for the aims of this study have also been included in order to keep useful information. The values of all indices and attributes in each sampled point are presented in Table 2. Measured richness and family richness were the best metrics to discriminate between impact and nonimpact places showing strong significant differences $(P=0.000023$ and $P=0.00028$, resp.). BMWP/Col and S-W indices also showed significant differences, although less powerful than the previous ( $P=0.0012$ and 0.025 , resp.).

3.3. Richness Estimation. The nonparametric estimator Jack 2 predicted a high value of regional richness for the study area (93 taxa) (Figure 3). We assume that this value could be 

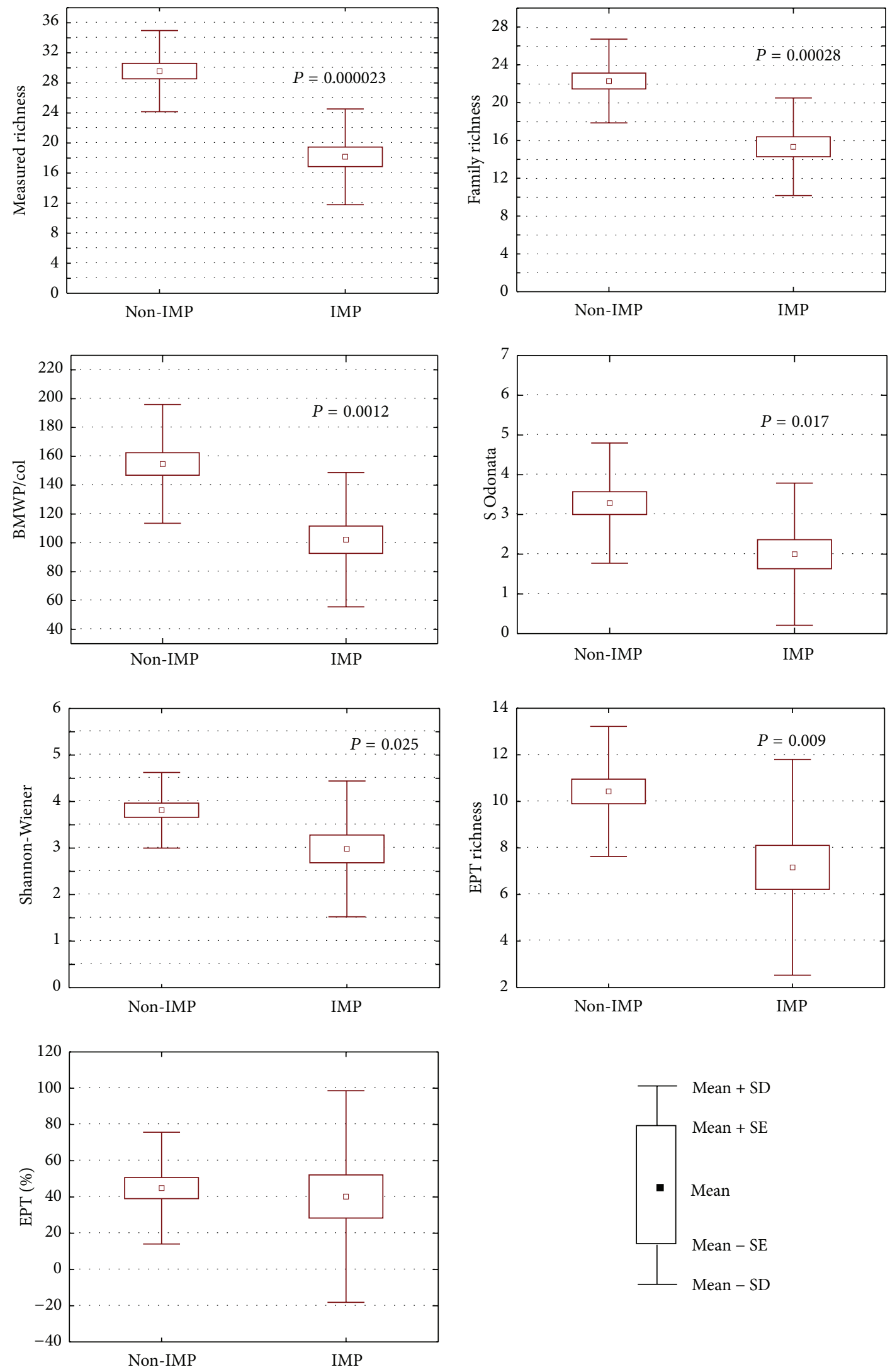

(a)

FIgure 2: Continued. 

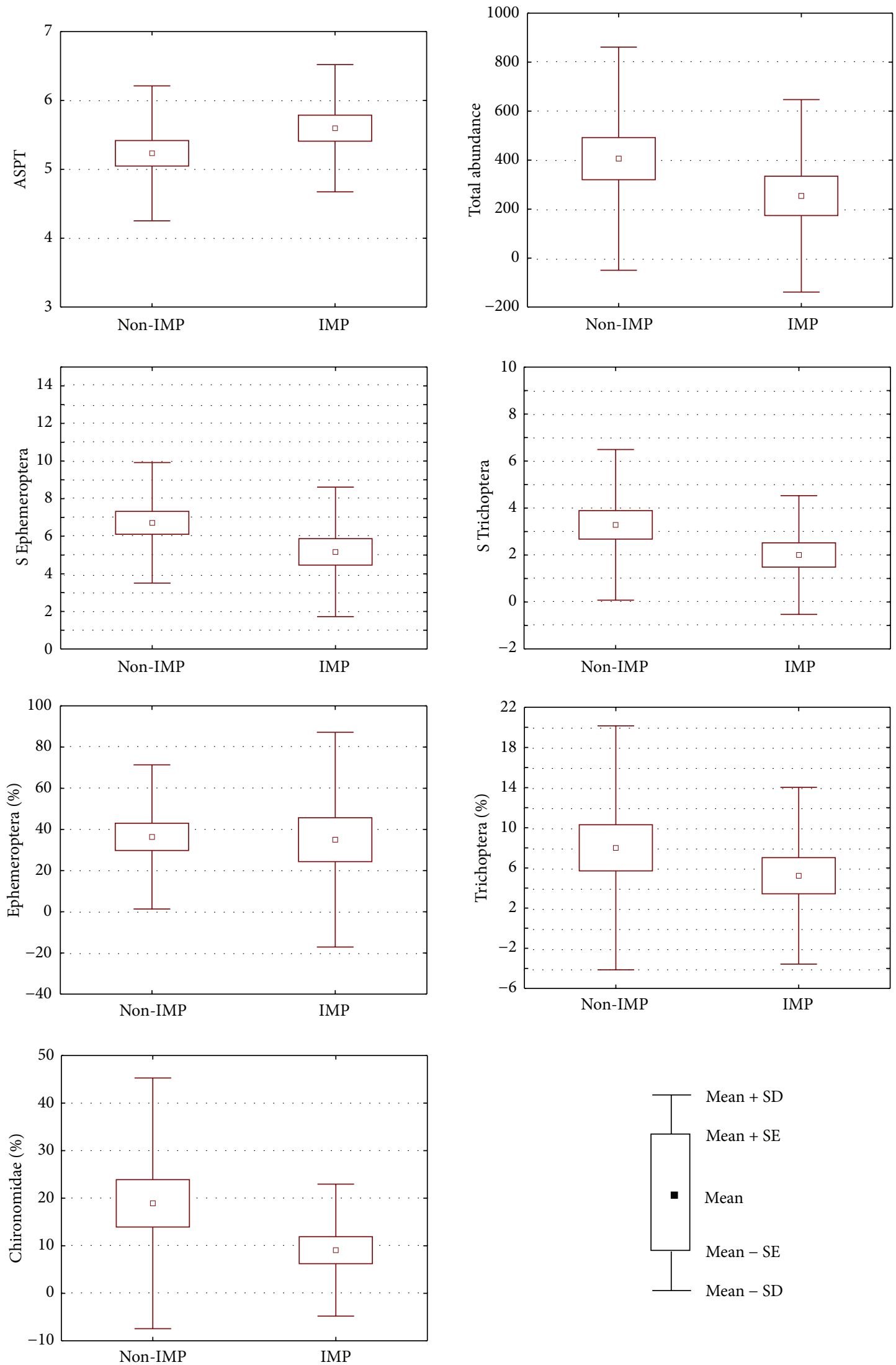

(b)

FIGURE 2: Response of several analyzed metrics to human impact on the studied streams. S: richness; \%: percentage of abundance. 


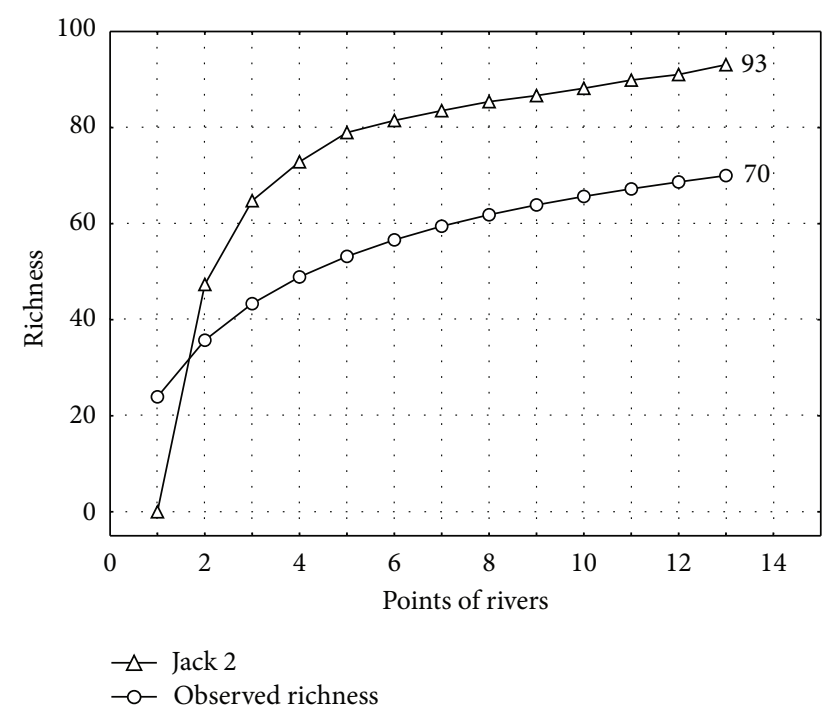

FIGURE 3: Observed and estimated regional richness in the study area. The nonparametric estimation was obtained by the nonparametric estimator Jackknife 2 (Jack 2).

used as a reference to calculate the percentage of real fauna collected in each river (Table 2), due to the fact that the distance between sampling points is not very high (Figure 1) and the orographic is very smooth. Only the nonimpact places presented values higher than $25 \%$. On the other hand, the parametric estimator Clench estimated a value of regional richness slightly larger than the observed richness (84 taxa) and we tested the inventory quality from its parameters: $a$ (30.3427), $b$ (0.3625), and determination coefficient (0.998). Only $83 \%$ of the total taxa were collected according to Clench estimations and 53 sampling points would be required to collect $95 \%$ of the total taxa.

\section{Discussion}

The results showed the importance of taxa richness, the principal and simplest structural property characterizing the macroinvertebrate community [40], to reflect the effects of human impact on coastal tropical streams. Measured richness and family richness were the best metrics to discriminate between impact and nonimpact places and, in the analysis of each of the macroinvertebrate orders, only EPT and Odonata richness proved to be suitable. Moreover, this study highlights the right performance of adoption of the classic index BMWP to Colombia (BMWP/Col [10]) and Shannon-Weiner indices. The good performance of these two biological indices is in accordance with our expectations and other studies [24, 41], as well as EPT richness that decreases with the drop of water quality [42] and Odonata richness, showing the same negative response [43]. Nevertheless, it may come surprising that richness had better results than these classic metrics, due to occasional poor sensitivity and high variability of the simplest metrics showing disturbances of low intensity or frequency [20]. In spite of this, taxa number has been successfully used in bioindication throughout the world for a long time, that is, in South America [16], North America [44], Africa [45], and Europe [46]. Why does richness perform adequately here? Ecuador has the highest biotic diversity per unit area among the South American countries [47]. In particular, western Ecuador harbors an exceptionally rich biota and consequently is listed by Conservation International as one of 25 global biodiversity hotspots [48]; this is made evident by the high number of taxa found in this study (70 taxa in only 53 minutes of sampling). The greatest biotic richness is frequently found in small and medium sized streams, as the ones in our study, where environmental variability, mainly in temperature, might be large, consequently creating a high number of niches [49]. Not intense human disturbances could affect more hardly the quality and integrity of several functional niches than in other lotic system types. Moreover, in temperate regions where most studies that reflect the uncertain performance of richness in bioindication have been carried out (see [50]), it is possible that a slight disturbance only lowers abundance but not necessarily richness [51]. Cautious analysis will be needed after, since tropical streams differ from their temperate counterparts in many characteristics, including evolutionary history, precipitation patterns, and water temperature, indicating that theories developed mainly for the temperate region may not apply to tropical regions [52]. Regardless of the possible causes and conjectures for this subject and according to the results of this study, we recommend taxa richness as the principal tool considered to reflect human impact, even in front of the classical indices used for this purpose. Furthermore, the same substratum type of the rivers included in this study (Table 2) minimized the effects of this variable on richness, despite the fact that it used to be commonly found in other studies as important. Also we suggest it to be used as baseline for the management and conservation of these types of lotic systems. In addition, this is the first report of performance of BMWP/Col test in the area, appearing together with S-W and EPT richness as adequate options for bioindication.

On the other hand, metrics frequently used on bioindication studies, here only showed a slight right trend (Ephemeroptera, Trichoptera, and Chironomidae attributes) or incorrect performance (ASPT and \% EPT). Both mayflies and caddisflies are sensitive to environmental stress [17]. However, their use in bioindication should be carried out considering the geographical patterns of taxa distribution and their adaptation to environmental conditions. Several orders and families of macroinvertebrates in South America show different altitudinal and latitudinal distribution patterns. For example, the diversity of families and genera of order Plecoptera in southern areas of the continent increases in most Equatorial areas, and even within Equatorial areas there are specific altitudinal variations in the same taxa [19]. The latitudinal gradient in diversity is one of the most pervasive patterns characterizing life on earth. Unfortunately, our understanding of how taxonomic richness of stream invertebrates related to latitude is poor [53], affecting undesirably the correct use of these metrics to assess the quality status of streams in this region. In addition, the tolerance to perturbations of taxa adapted to different environmental conditions 
can be variable $[17,54]$ and using order or even family information can be incorrect, thus adversely affecting the results on the ecological quality. There are some taxa which are widely distributed (e.g., Anacroneuria, Baetodes, Thraulodes, Leptohyphes, and Hydroptila) with different adaptation types according to the environmental inhabitation. Consequently, assigning average value of tolerance for them could lead to erroneous result of quality. Therefore, we suggest that, although they showed suitable performance here (but not significant), the use of Trichoptera and Ephemeroptera taxa as bioindication parameters in this region must be taken only as complement and reinforcement to the previously discussed techniques. More extensive studies of latitudinal and adaptation partners of these taxa in South America would be necessary to get to the bottom of their real performance on stream bioindication. Regarding Chironomidae, it is known that they are frequently more abundant in locations affected by organic effluents, although only half of chironomids taxa follow this pattern [45]. We believe this might be the case in the present study. However, our taxonomic identification level for chironomids does not allow identifying which species are being affected by water quality, showing only one trend. Chironomidae does not seem to be a good indicator of water quality, unless it includes the exact percentage of sensitive taxa. Finally, a high ASPT is considered indicative of a clean site containing large numbers of high scoring taxa [21]. However, other authors question the reliability of ASPT [55] due to the fact that this index displays the average tolerance of all taxonomic groups represented within the study site but does not take into consideration their relative numbers. Moreover, in fluctuating streams where some orders as Plecoptera are less abundant, the use of these metrics cannot be suitable [11]. In this study, neither the use of ASPT nor the \% EPT can be proposed, because they showed the contrary trend of performance in terms of bioindication. More thorough research about these indices in this region to assess their suitable use must be carried out in the future.

Finally, to properly recommend the use of taxa richness as principal parameter of bioindication, we must mention three fundamental aspects. The taxonomic level used, the ranks of quality, and the effort-results relationship. It has been widely discussed what the best taxonomic level used for bioindication studies is [56]. While it is true that the best level used would be species, taxonomic studies of some taxa make practically unviable work in many countries due to high economic cost required in training the specialist taxonomists, especially in Diptera (and particularly Chironomidae) [13]. An appropriate balance between quality outcomes and time is adjusted using the family as taxonomic level. By doing so, the advantages of macroinvertebrates as bioindicators are maintained at this level and thus it is recommended in many of protocols and studies also [11]. In some cases, including the present research, different taxonomic levels are used, for example, genus in Trichoptera, Plecoptera, and Ephemeroptera and family in Diptera [20]. In this study more than $50 \%$ of taxa were identified up to genus, which has been taken as a feasible and reliable surrogate of species richness [40]. On the other hand, the most used indices on bioindication have quality ranges for their values. Mason
[57] and Chapman [7] classify water quality as good where BMWP and ASPT exceed 100 and 4.3, respectively. ShannonWiener values lower than 1.5 are considered as low diversity, between 1.6 and 3.0 as medium diversity, and higher than 3.1 as high diversity [40]. In this study we propose a richness measure percentage value to indicate human alterations in these streams. Only the nonimpact places present values over $25 \%$; therefore, we recommend that the sampled points showing taxa richness under $25 \%$ of true regional richness are considered as altered by anthropogenic impact on future evaluations. This regional richness, provided that we can assume that all streams could have all taxa, will be obtained with Jack 2 nonparametric estimator and at least with four samples of three minutes each, the minimum to achieve the observed regional richness (Figure 3). This is only a first proposal to correctly use this simple metric regarding ranks and limits of quality. Furthermore, according to Clench, we collected $83 \%$ of the existing taxa carrying out only samplings of three minutes in each place. We think that it is an acceptable value on bioindication studies; besides, 40 more samples of the 13 listed in this study would be necessary to catch up $95 \%$ of the overall samples (only 120 extra minutes to collect $12 \%$ more).

This study seeks to make the baseline of use of taxa richness as bioindicators and presents the first taxon list of this region. The limited sample numbers that we were able to get, due to social conflicts and other risks of the study area, do not allow reaching conclusions that are widely extrapolated to other areas; consequently, simple speculations of the possible causes can be made. Nonetheless, we believe that these results are clear enough and statistically significant to recommend which attributes, from those largely used, and how they must be utilized as quality indicators for these streams. Through this study a great path is opened to research and establish the baseline to develop a multimetric index that includes metrics suitable for this region (principally taxa richness, EPT richness, S-W, and BMWP/Col or an own adaptation of this to study area) and the design of a sampling protocol including the most robust richness estimator, both nonparametric (Jack 2 ) and parametric (Clench), to establish sampling times and value ranks for the several used attributes.

\section{Conflict of Interests}

The authors declare that there is no conflict of interests regarding the publication of this paper.

\section{Acknowledgment}

This research was funded by the CID (Research and Development Center) (PUCESE).

\section{References}

[1] W. Thuiller, "Biodiversity: climate change and the ecologist," Nature, vol. 448, no. 7153, pp. 550-552, 2007.

[2] L. Kaufman, "Catastrophic change in species-rich freshwater ecosystems: the lessons of Lake Victoria," BioScience, vol. 42, pp. 846-858, 1992. 
[3] C. M. Pringle, F. N. Scatena, P. Paaby-Hansen, and M. Nunez Ferrera, "River conservation in Latin America and the Caribbean," in Global Perspectives on River Conservation: Science, Policy and Practice, P. J. Boon, B. Davies, and G. E. Petts, Eds., pp. 41-77, John Wiley and Sons, Durham, NC, USA, 2000.

[4] R. P. King and I. B. Ekeh, "Status and seasonality in the physicochemical hydrology of a Nigerian headwater stream," Acta Hydrobiologica, vol. 32, no. 3-4, pp. 313-328, 1990.

[5] D. Jacobsen, "The effect of organic pollution on the macroinvertebrate fauna of Ecuadorian highland streams," Archiv für Hydrobiologie, vol. 143, no. 2, pp. 179-195, 1998.

[6] D. Ros, La contaminación del agua en el Ecuador una aproximación económica, Instituto d Investigaciones Económicas, Quito, Ecuador, 1995.

[7] D. Chapman, Water Quality Assessments. A Guide to Use of Biota, Sediments and Water in Environmental monitoring, Chapman and Hall, 1996.

[8] R. K. Johnson, "Spatiotemporal variability of temperate lake macroinvertebrate communities: detection of impact," Ecological Applications, vol. 8, no. 1, pp. 61-70, 1998.

[9] R. Figueroa, C. Valdovinos, E. Araya, and O. Parra, "Macroinvertebrados bentónicos como indicadores de calidad de agua del sur de Chile," Revista Chilena De Historia Natural, vol. 76, pp. 275-285, 2003.

[10] H. Zamora, "Adaptación del índice BMWP para la evaluación de la calidad de las aguas epicontinentales en Colombia," Unicauca-Ciencia, vol. 4, pp. 47-60, 1999.

[11] E. Domínguez and H. R. Fernández, Calidad de los ríos de la Cuenca del Salí (Tucumán, Argentina) medida por un índice biótico, Serie Conservación de la Naturaleza. No. 12, Fundación Miguel Lillo, Tucumán, Argentina, 1998.

[12] R. Arocena, "La comunidad bentónica como Indicadora de zonas de degradación y recuperación en el Arroyo Toledo (Uruguay)," Revista de Biología Tropical, vol. 43, pp. 643-655, 1996.

[13] R. Acosta and N. Prat, "Chironomid assemblages in high altitude streams of the Andean region of Peru," Fundamental and Applied Limnology, vol. 177, no. 1, pp. 57-79, 2010.

[14] D. F. Baptista, D. F. Buss, M. Egler, A. Giovanelli, M. P. Silveira, and J. L. Nessimian, "A multimetric index based on benthic macroinvertebrates for evaluation of Atlantic Forest streams at Rio de Janeiro State, Brazil," Hydrobiologia, vol. 575, no. 1, pp. 83-94, 2007.

[15] O. Fossati, J.-G. Wasson, C. Héry, G. Salinas, and R. Marín, "Impact of sediment releases on water chemistry and macroinvertebrate communities in clear water Andean streams (Bolivia)," Archiv für Hydrobiologie, vol. 151, no. 1, pp. 33-50, 2001.

[16] R. Acosta, B. Ríos, M. Rieradevall, and N. Prat, "Propuesta de un protocolo de evaluación de la calidad e Guardar ecológica de ríos andinos (CERA) y su aplicación a dos cuencas en Ecuador y Perú," Limnetica, vol. 28, no. 1, pp. 35-64, 2009.

[17] N. Bonada, N. Prat, V. H. Resh, and B. Statzner, "Developments in aquatic insect biomonitoring: a comparative analysis of recent approaches," Annual Review of Entomology, vol. 51, pp. 495-523, 2006.

[18] P. J. Pave and M. Marchese, "Invertebrados bentónicos como Indicadores de calidad del agua en ríos urbanos (Paraná-Entre Ríos, Argentina)," Ecologycal Society of Australia, vol. 15, pp. 183-197, 2005.
[19] S. Tomanova, P. A. Tedesco, M. Campero, P. A. Van Damme, N. Moya, and T. Oberdorff, "Longitudinal and altitudinal changes of macroinvertebrate functional feeding groups in neotropical streams: a test of the River Continuum Concept," Fundamental and Applied Limnology, vol. 170, no. 3, pp. 233-241, 2007.

[20] N. Prat, B. Ríos, R. Acosta, and M. Rieradevall, "Los macroinvertebrados como indicadores de calidad de las aguas," in Macroinvertebrados bentónicos sudamericanos. Sistemática y biología, E. Domínguez and H. R. Fernández, Eds., p. 656, Fundación Miguel Lillo, Tucumán, Argentina, 2009.

[21] P. D. Armitage, D. Moss, J. F. Wright, and M. T. Furse, “The performance of a new biological water quality score system based on macroinvertebrates over a wide range of unpolluted running-water sites," Water Research, vol. 17, no. 3, pp. 333-347, 1983.

[22] J. Alba-Tercedor, P. Jáimez-Cuéllar, M. Álvarez et al., "Caracterización del estado ecológico de ríos mediterráneos ibéricos mediante el índice IBMWP (antes BMWP')," Limnetica, vol. 21, no. 3-4, pp. 175-182, 2004.

[23] B. C. Chessman, "Rapid assessment of rivers using macroinvertebrates: a procedure based on habitat-specific sampling, family level identification and a biotic index," Australian Journal of Ecology, vol. 20, no. 1, pp. 122-129, 1995.

[24] M. N. Strieder, L. H. Ronchil, C. Stenert, R. T. Scherer, and U. G. Nesiss, "Biological measures and water quality indices in a micro-watershed polluted with urban and tannery sewage in South Brazil," Acta Biologica Leopoldensia, vol. 28, no. 1, pp. 1724, 2006.

[25] L. Pizzolon and M. Miserendino, "The performance of two regional biotic indices for running water quality in Northern Patagonian Andes," Acta Limnologica Brasiliensa, vol. 13, pp. 1127, 2001.

[26] H. R. Fernández, F. Romero, and E. Domínguez, "Intermountain basins use in subtropical regions and their influences on benthic fauna," River Research and Application, vol. 24, pp. 1-13, 2008.

[27] V. M. Junqueira and S. C. M. Campos, "Adaptation of the BMWP method for water quality evaluation to Rio das Velhas watershed (Minas Gerais, Brazil)," Acta Limnologica Brasiliensia, vol. 10, pp. 125-135, 1998.

[28] J. Giacometti and F. Bersosa, "Macroinvertebrados acuáticos y su importancia como bioindicadores de calidad del agua en el río Alambí," Boletín Técnico 6, vol. 2, pp. 17-32.

[29] L. R. Holdridge, W. C. Gmlke, W. H. Hatheway, T. Liang, and J. R. . Tosi, Forest Environments in Tropical Life Zones: A Pilot Study, Pcrgmon, Oxford, UK, 1971.

[30] N. L. Poff and J. V. Ward, "Implications of streamflow variability and predictability for lotic community structure: a regional analysis of streamflow patterns," Canadian Journal of Fisheries and Aquatic Sciences, vol. 46, no. 10, pp. 1805-1818, 1989.

[31] S. Fenoglio, G. Badino, and F. Bona, "Benthic macroinvertebrate communities as indicators of river environment quality: an experience in Nicaragua," Revista de Biologia Tropical, vol. 50, no. 3-4, pp. 1125-1131, 2002.

[32] J. Biggs, P. Williams, M. Whitfield, G. Fox, and P. Nicolet, Biological Techniques of Still Water Quality Assessment: Phase 3. Method Development, Environment Agency, Bristol, UK, 2000.

[33] P. D. Armitage and I. Pardo, "Impact assessment of regulation at the reach level using macroinvertebrate information from mesohabitats," Regulated Rivers, vol. 10, no. 2-4, pp. 147-158, 1995. 
[34] H. R. Fernández and E. Domínguez, Guía Para La Determinación De Los Artrópodos Bentónicos Sudamericanos, Universidad Nacional De Tucumán, Facultad De Ciencias Naturales e Instituto, 2001.

[35] R. W. Holzenthal, R. J. Blahnik, A. L. Prather, and K. M. Kjer, "Order Trichoptera Kirby, 1813 (Insecta), Caddisflies," Zootaxa, no. 1668, pp. 639-698, 2007.

[36] A. Foggo, S. D. Rundle, and D. T. Bilton, "The net result: evaluating species richness extrapolation techniques for littoral pond invertebrates," Freshwater Biology, vol. 48, no. 10, pp. 17561764, 2003.

[37] A. S. Melo and C. G. Froehlich, "Evaluation of methods for estimating macroinvertebrate species richness using individual stones in tropical streams," Freshwater Biology, vol. 46, no. 6, pp. 711-721, 2001.

[38] R. K. Colwell and J. A. Coddington, "Estimating terrestrial biodiversity through extrapolation," Philosophical transactions of the Royal Society of London B, vol. 345, no. 1311, pp. 101-118, 1994.

[39] R. K. Colwell, Estimates: StatiStical Estimation of Species Richnes and Shared Species From Samples, Version 7. USer's Guide and Application, University of Connecticut, Storrs, Conn, USA, 2004, http://purl.oclc.org/.

[40] A. E. Magurran, ,Measuring Biological Diversity, Blackwell Publishing, Oxford, UK, 2004.

[41] M. P. Silveira, D. F. Baptista, D. F. Buss, J. L. Nessimain, and M. Egler, "Application of biological measures for stream integrity assessment in south-east Brazil," Environmental Monitoring and Assessment, vol. 101, no. 1-3, pp. 117-128, 2005.

[42] C. I. Weber, "Biological field and laboratory methods for measuring the quality of surface waters and effluents," Tech. Rep. EPA-670/4-73-001, Environmental Protection Agency, Cincinnati, Ohio, USA, 1973.

[43] T. E. Clark and M. J. Samways, "Dragonflies (Odonata) as indicators of biotope quality in the Kruger National Park, South Africa," Journal of Applied Ecology, vol. 33, no. 5, pp. 1001-1012, 1996.

[44] D. R. Barton, "The use of Percent Model Affinity to assess the effects of agriculture on benthic invertebrate communities in headwater streams of southern Ontario, Canada," Freshwater Biology, vol. 36, no. 2, pp. 397-410, 1996.

[45] F. O. Arimoro, R. B. Ikomi, and E. Efemuna, "Macroinvertebrate community patterns and diversity in relation to water quality status of River Ase, Niger Delta, Nigeria," Journal of Fisheries and Aquatic Science, vol. 2, no. 5, pp. 337-344, 2007.

[46] J. M. Hellawell, Biological Surveillance of Rivers: A Biological Monitoring Handbook, Natural Environmental Research Council, Water Research Centre, 1978.

[47] R. W. Sites, M. R. Willig, and M. J. Linit, "Macroecology of aquatic insects: a quantitative analysis of taxonomic richness and composition in the andes mountains of Northern Ecuador," Biotropica, vol. 35, no. 2, pp. 226-239, 2003.

[48] R. A. Mittermeier, N. Myers, and C. G. Mittermeier, Hotspots: Earth's Biologically richest and most Endangered terrestrial ecoregions, University of Chicago Press, Chicago, Ill, USA, 2000.

[49] R. L. Vannote, G. W. Minshall, K. W. Cummins, J. R. Sedell, and C. E. Cushing, "The river continuum concept," Canadian Journal of Fisheries and Aquatic Sciences, vol. 37, no. 1, pp. 130137, 1980.

[50] C. L. Wenn, "Do freshwater macroinvertebrates reflect water quality improvements following the removal of point source pollution from Spen Beck, West Yorkshire," Earth and Environment, vol. 3, pp. 369-406, 2008.

[51] R. G. Death, "The effect of patch disturbance on stream invertebrate community structure: the influence of disturbance history," Oecologia, vol. 108, no. 3, pp. 567-576, 1996.

[52] J. K. Jackson and B. W. Sweeney, "Present status and future directions of tropical stream research," Journal of the North American Benthological Society, vol. 14, no. 1, pp. 5-11, 1995.

[53] B. A. Hawkins, "Ecology's oldest pattern," Trends Ecology and Evolution, vol. 15, pp. 390-391, 2001.

[54] C. R. Townsend and A. G. Hildrew, "Species traits in relation to a habitat templet for river systems," Freshwater Biology, vol. 31, pp. 265-275, 1994.

[55] P. E. Kirsch, "Benthic Macroinvertebrate Diversity and Biotic Indices Analysis of Lakes Wrights, Springfield, Mc Grath, Kearney and Morris, and an Upgraded Analysis of Lakes Dollar, Russell, Stillwater, Papermill and Kinsac within the Halifax Regional Municipality (HRM), Nova Scotia, Canada," Project E-3, Soil and Water Conservation Society of Metro Halifax, 1999.

[56] A. S. Melo, "Effects of taxonomic and numeric resolution on the ability to detect ecological patterns at a local scale using stream macroinvertebrates," Archiv für Hydrobiologie, vol. 164, no. 3, pp. 309-323, 2005.

[57] C. F. Mason, Biology of Freshwater Pollution, Prentice Hall, London, UK, 4th edition, 2002. 

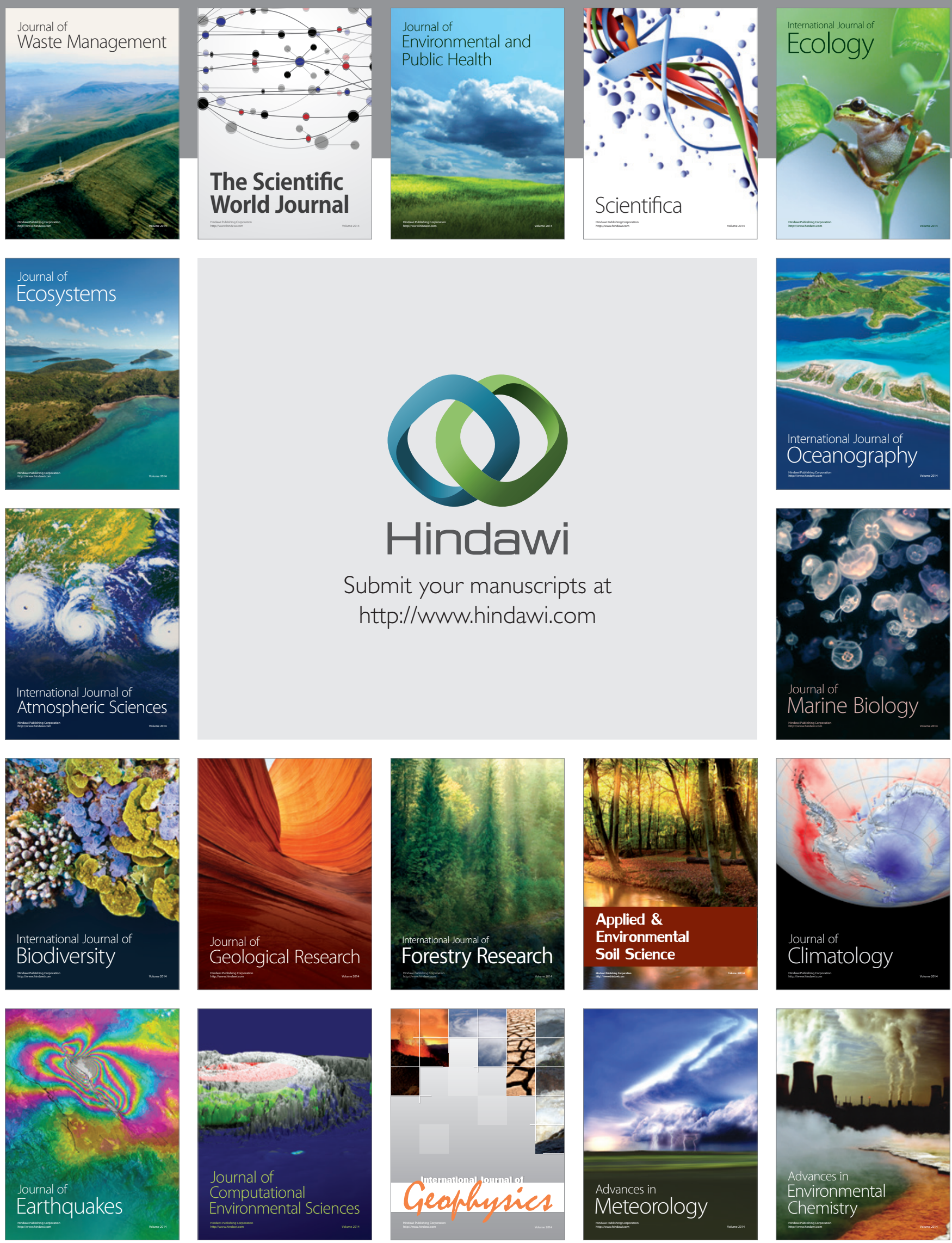